\title{
A New Model of the Framework for the Influence of the Internet of Things (IoT) Usage on the Grassroots Innovators' Sustainability
}

\author{
Sharmila Mohamed Salleh ${ }^{1 *}$ and Norzaidi Mohd Daud ${ }^{1}$ \\ ${ }^{\text {I} F a c u l t y ~ o f ~ B u s i n e s s ~ M a n a g e m e n t, ~ U n i v e r s i t i ~ T e k n o l o g i ~ M A R A, ~} 40450$ Selangor, Malaysia
}

\begin{abstract}
This paper aims to examine the influence of Internet of Things (IoT) usage on grassroots innovators' sustainability in Malaysia. The study is one of the first to address IoT usage on grassroots innovators' sustainability in Malaysia. It is a much-needed new model of the framework for the influence of the Internet of Things (IoT) usage on the grassroots innovators by determining and expanding the two factors (i.e. perceived usefulness and perceived ease of use) on the sustainability of grassroots innovators in Malaysia. This framework integrate principal element, act as a basis in establishing the development of conceptual framework. The study suggested for grassroots innovators to gain full advantage of IoT functions and applications and contribute as part of the active nation's interest towards a knowledge-based economy. The study focuses on grassroots innovators in Malaysia. The only database available is at Malaysia Innovation Foundation /Yayasan Inovasi Malaysia (YIM). A sample is obtained from 335 grassroots innovators in seven zones across Malaysia. The study is one of the first to address IoT usage on grassroots innovators' sustainability in Malaysia. The data will be analysed using structural equation modelling (SEM) to ensure the accuracy and validity of the findings. SEM is expected to demonstrate the influence of IoT usage to enable the sustainability of grassroots innovators in Malaysia. The results should provide insights on how the grassroots innovators in Malaysia and similar communities in other countries can sustain their innovation capacity by using IoT.
\end{abstract}

Keywords: grassroots innovators; grassroots innovation; internet of things (IoT); sustainability

\section{INTRODUCTION}

According to Leminen et al. (2018), IoT plays a significant role in everyday life of everyone in the universe. It bundles together diverse "things" and systems and supports the integration of different fields of knowledge, technologies, and communications solutions. IoT leads the service business as connectivity and smart components become more important than the physical element of the "thing". IoT has the potential to make the physical world economically liquid, personalised, and efficient (Brody \& Pureswaran, 2015). Products and their functionalities will be offered as services, while "things" will be associated with the services they deliver (Atzori et. al., 2010; Decker \& Stummer, 2017). An increasing number of connected "things" creates opportunities for fitting the digital and physical worlds together (Gershenfeld \& Vasseur, 2014). In layman's terms, IoT is an enabler in system integration, services, and application function that allows humans and objects to communicate using the Internet with constant connectivity, remote control ability, and data sharing at greater efficiency 24/7. This will affect human behaviours (Gao \& Bai, 2014) in managing their lives and businesses.

According to Nolin and Olson (2016), in the promotion of IoT, the European Union (EU) policymakers emphasise that "devices and tags can interact with the environment and send the information to other objects through machine-tomachine communication" (The Council of Europe, 2009, p. 7). Based on the strategic documents of the Commission of The European Communities (2008; 2009), "smart" concepts involve smart and seamless connectivity between devices and 
intelligent cars, machines, and smart buildings, as well as communication between humans and things. IoT and its applications enhance smart city development to be equipped with smart parking, smart urban lighting, integrated transport system, water management, telecare, smart city maintenance, women safety mechanisms, digital signature issues, smart grid system and so on.

The above statement supports the opportunities of IoT usage that are widely applied in China, India, Europe and the United States (U.S.) to boost the global Knowledge Economy Concept trajectory. It is expected to bring many opportunities benefitting the information technology (IT) industry by trillions of dollars (Chatterjee \& Kar, 2018). In fact, in a smaller scale, IoT can be applied in a home network to control physical appliances (Grau, 2013) and widely used in agriculture to enhance output and weather forecast (Jayashankar et al., 2018).

Furthermore, it shows that the importance and significance of IoT can be expanded widespread to the entire Asia region, including Malaysia. Along the way of IoT usage, one must relate IoT with sustainability. Sustainability refers to the ability to consistently uphold certain values in the three major areas of environmental issues, societal structures, and economic importance (Nicolosi et al., 2018). To further align with the present study on grassroots innovators' sustainability in Malaysia, the outcome of sustainability on certain initiatives will become a central principle to be addressed. The study believes that innovation and IoT usage are the best media to improve social well-being among the grassroots community.

Nevertheless, a problem still needs to be addressed on how innovation and IoT should be fostered as a toll for grassroots sustainability. A study conducted by Mohamed et al. (2012) showed that information and communications technology (ICT) is a medium to reduce the poverty gap between urban and rural communities. ICT is broadly defined as an infrastructure consisting of all devices, networking components, applications, and systems to be streamlined for use by people and organisations to communicate in a digital manner (Rouse, 2005). Being a hot topic globally, digital divide is a major issue, especially in developing countries like Pakistan (Mujahid, 2001), where the need for government intervention in policy-making is crucial.
In Malaysia, the digital gap between urban and rural is hugely discussed and narrowed down to the community by sectors (Horn \& Rennie, 2018). Income inequality also has bad influences on Malaysia's ethnicity (Siwar et al., 2016). According to the infographic by Department of Statistics Malaysia in 2016, the lowest median income gap in rural areas of the country stands at RM3,08o due to the probability of rural household earnings mainly coming from agriculturalbased jobs and the never-ending economic injustice. Nevertheless, a study conducted by Mohamed et al. (2012) showed that ICT is a medium to reduce the poverty gap. As proven in Malaysia's ICT ecosystem, science, technology, and innovation have been identified as the key elements and catalysts for economic output, social well-being, innovation, and creativity.

In the 1990s, Malaysia established Cyberjaya and Putrajaya as new federal administrative capitals and hubs for knowledge economy to promote multimedia and services. Malaysia has put forward the focus on innovative digital technology and economy as a foundation of a sustainable nation in Digital Government Strategy, Economic Transformation Programme, and Government Transformation Programme. In order to further help with the bottom 40\% income level (B40) agenda, the government agency Malaysia Digital Economy Corporation Sdn Bhd launched eRezeki in 2015 to accelerate the digitalisation and modernisation of job creations and online jobs in a conducive crowdsourcing ecosystem. As such, people with income lower than $\mathrm{RM}_{4}, \mathrm{OOO}$ are eligible to get a job online with their skillset.

Nevertheless, due to the digital and poverty gaps, there are insufficient economic activities and opportunities left to be grabbed that are directly related to benefit the B40 group, especially grassroots innovators. On the other hand, grassroots innovators use alternative solutions in agriculture, ecological housing, transportation, economy transaction, community enterprises, digital common hub, and cultural diversity to sustain themselves (Nicolosi et al., 2018). In fact, it was shown that the digital divide affected people in remote areas in accessing the technology and they also have fears of picking up new technology due to limitation in language (Horn \& Rennie, 2018). 
In this study, grassroots innovator is an individual from rural areas using their own creativity of tacit knowledge and traditional skills inherited for generations to produce, enhance, and add value to the existing products or services within the limitation of resources to ensure sustainability. Therefore, the grassroots innovations can be replicated, adapted, and reengineered elsewhere. Grassroots innovation is referred to as an innovative product or service (Nasir \& Subari, 2017) developed to ease the daily chores and overcome hurdles in the common and ordinary community or masses.

The previous study realised the importance of an initiative introduced by Malaysia Innovation Foundation or Yayasan Inovasi Malaysia (YIM) since its establishment in October 2010 in promoting innovation and facilitating its development. The outreach activities at grassroots community that were previously performed via physical discovery are now conducted on an online platform, resulting in the creation of different scenarios for the community to participate. As a smartphone was used as a tool to discover these innovations, YIM realised that the grassroots community was faced with limitations and difficulties to use the technology of IoT applications.

The report showed that inconsistencies occurred, whereby significant reduced numbers of impactful grassroots innovations were discovered when smartphones were used as a medium of innovation submission (Omar et al., 2016).

Furthermore, it is shown that:

i) Grassroots innovators are reluctant to participate using smart connection;

ii) Grassroots innovators are at ease within their networks (Martin \& Upham, 2016) and incompatible with the industries' profit intention at the mainstream economy level (Smith et al., 2014); and

iii) Grassroots innovators are not keen to work in silo and the importance of social support is shared in the dimensions of membership, influence, reinforcement, and shared emotional connection (Martiskainen, 2017).

In fact, grassroots innovator's sustainability is a crucial and vital element to translate and accelerate the social well-being of the nation as much as the government's effort to establish many programmes related to science, technology, and innovation in elevating poverty (Siwar et al., 2016). The imbalance and inequality between communities for ICT connectivity (Tahir et al., 2016), technology resistance (Mohd Daud \& Mohamed, 2009), efficacy to adapt technology (Mohd Daud et al., 2013), the tremendous growth of IoT from users and organisations ( $\mathrm{Lu}$ et al., 2018) effectively gave relative impact towards the grassroots innovators' sustainability in Malaysia.

Therefore, the main objective of this study is to determine the influence of IoT usage on grassroots innovators' sustainability.

\section{The application of IoT}

In the current world, it is said that IoT is a tool that translates business innovations into economic development (Yu et al., 2016). It was shown that there were areas to be improvised in new high-tech IoT ventures and network integration between internal and outside players in order to gain novel offerings and match the entrepreneurial and market needs. In India, IoT is widely used in agriculture to enhance output and weather forecast (Jayashankar et al., 2018). Meanwhile, in China, IoT is perceived to make an influential impact on economic development (Yu et al., 2016).

According to Zhang and Mahadevia (2014), multiple innovations using IoT can be adapted locally by farmers at rural areas in improving the agricultural farming practices and local adaptation of farming practices.

\section{The Sustainability of Grassroots Innovators}

According to Nicolosi et al. (2018), sustainability refers to the ability to consistently uphold certain values or interests for the longest time. Generally, sustainability is the positive result sought from the initiatives done for social, environmental, and economic reasons. Consequently, the next generation will continue enjoying the benefits for the longest period.

In the case of this study, sustainability focuses on grassroots innovators, whereby the innovators are the actors within the field (Davies, 2012). The four main types of innovations that are important in ensuring sustainability are as listed below:

i) Product innovation sustainability refers to upscaling in performance or technical setting;

ii) Process innovation sustainability refers to upscaling in the production and delivery 
process;

iii) Marketing innovation sustainability refers to upscaling in product packaging and a new channel of business performance; and

iv) Organisational innovation sustainability refers to the alternative solution for internal or external business practices and standard.

To further align with this study on grassroots innovators' sustainability in Malaysia, the sustainability of certain initiatives will become a central principle to be addressed. The study believes that innovation and new technology are the best media to improve social well-being. Having said so, a problem still needs to be addressed on how innovation and technology should be fostered using technology as a medium for grassroots innovators' sustainability.

According to Siwar et al. (2016), even though there is an indication of an upward trend of household income for both rural and urban communities from 1970-2012, the income gap in rural and urban areas of the country is still huge and the status quo (rich-poor) remains. For these rationales, technology acceptance, social influence, diffusion of technology, and technology resistance are cascaded to the new theoretical and conceptual framework.

\section{THE MODEL}

By employing the three models, i.e. Technology Acceptance Model (TAM), Unified Theory of Acceptance and Use of Technology (UTAUT), and Diffusion of Innovation Theory (DOI), the study appends below the relevant theoretical framework that may assist to establish a relationship among those variables towards the influence of IoT usage on the grassroots innovators' sustainability in Malaysia.

Meanwhile, technology resistance from the advancement of Task-Technology Fit (TTF) is selected to be integrated into the conceptual framework as well.

In order to be sustainable, grassroots innovators need to realise the importance of IoT application in their life. The use of IoT in smartphone applications can contribute as a tool for grassroots innovators' sustainability in Malaysia. To ensure a smooth and manageable scope of research, 10 factors are considered and the following hypotheses will be discussed:

\section{A. Perceived Usefulness and Internet of Things} (IoT) Usage

A previous study found that TAM was the most used informal context setting on IT adoption; however, it was only limited to the general information on the aspect of technology novelty (Ghazali et al., 2018). Little empirical evidence has found the relationship of TAM's two key constructs with IoT usage. In many studies, the two key constructs of Perceived Ease of Use and Perceived Usefulness are hypothesised to directly influence users' intention to adopt the system and their future usage; however, it is yet to be tested on grassroots innovators' sustainability.

As a basis, TAM is useful and significant to the current study for its theoretical framework's general determinants, i.e. Perceived Usefulness (PU) and Perceived Ease of Use (PEOU). PU focuses on the user's subjective possibility of increasing performance when adopting a technology (Gao \& Bai, 2014). PU can be the basis for IoT usage. For example, when mobile phones were first introduced in Malaysia in 1985 (Osman et al., 2012), they were bulky and heavy. When the size became smaller and simpler, mobile phones were accepted and widely used not only by the professionals, but also for the general public's common use (Osman et al., 2012). According to (Osman et al., 2012), the finding indicated that the trend in the community to accept the technology is more significant as compared to actual needs.

Nevertheless, over the years, the need to use mobile phones or smartphones outnumbered the other categories of users as $72 \%$ of common users (Osman et al., 2012) contributed towards the peak of $131.8 \%$ mobile cellular penetration as reported by Malaysian Communications and Multimedia Commission (MCMC) in February 2018. This was supported by the availability of e-payment and confidence awareness programmes (NST, 2018).

Perceived usefulness (PU) is defined as the extent to which a person believes that using a system can enhance their job performance. In India, Mahatma Gandhi introduced Charkha (spinning wheel) as a symbol for many new technologyimprovising productions of grassroots products in rural areas and his efforts were recognised by the villagers as well as experts (Pattnaik \& Dhal, 2015). Comparison-wise in Malaysia, the new technique of combining aquaculture and hydroponics, i.e. aquaponics, has been introduced by a young 
man from Sabah, Azizul Jurilin. His limitation in resources and his technology knowledge gained from his training in Japan had helped him to come up with innovative solutions to curb many disturbing factors involving environmental issue, political ban, and economic factors. Now, his expertise and innovation are sought by more than 100 villagers following his footsteps in aquaponics.

PU emphasises on the positive effect of IoT usage as the ability of users to accept the Internet and its applications, which incorporates knowledge and consists of conveniences, interactiveness, intelligence, connectivity, telepresence, trust, safety, and privacy (Al-Momani et. al., 2016; Lu et al., 2018). Meanwhile, Kassim, Fatiany, Kader, and Hairuddin (2012) stated that the role of trust in the context of information system had a significant influence in mediating the acceptance level of users.

The study found that knowledge enhancement, trust, and safety when accumulated signified a positive effect on the behavioural intention to use IoT for grassroots innovators. Therefore, PU is significant as the theoretical basis to deepen the current study. The following hypothesis is proposed:

H1. Perceived usefulness is a predictor of Internet of Things (IoT) usage.

\section{B. Perceived Ease of Use and Internet of Things (IoT) Usage}

According to Al-Momani et al. (2016), TAM indicated that these two determinants, i.e. perceived usefulness and perceived ease of use, serve as the basis for attitudes towards using a particular system, which likely determines the intention to use and then generates the actual usage behaviour. Perceived ease of use (PEOU) refers to the user's expectation of ease to use when using the technology voluntarily (Davis, 1989; Hubert et al., 2018). For example, in the usage of smart home services (Hubert et al., 2018), there is positive acceptance to use smart home systems.

In addition to the above, IoT technology acceptance has a positive effect on the characteristics of fun and enjoyment $(\mathrm{Lu}$ et al., 2018). Therefore, this study acknowledges the importance of enjoyment as a variable of the study. In the article of Determinants of Perceived Ease of Use: Integrating Control, Intrinsic Motivation, and Emotion into the Technology Acceptance Model, Venkatesh (2004) found that control (self-efficacy and facilitating conditions), intrinsic motivation (computer playfulness), emotion (computer anxiety), and objective usability served as determinants of individuals' perceived ease of use about a new system.

In this particular study, PEOU has been expanded in-depth. New users will continue using the technology as their experience using the system is increased. Therefore, the study undertakes the task to verify the following hypothesis:

H2. Perceived ease of use is a predictor of Internet of Things (IoT) usage

\section{Perceived Ease of Use and Perceived Usefulness}

PEOU influences PU towards the usage of IoT. This study identified the interdependency of both variables. According to Ghazali et al. (2018), the ease of using new technology is certainly a positive effect. This was shown in his study on the easy access of mobile shopping via mobile phones, which resulted in the convenience of online shopping. On the other hand, in their study on the adoption and usage of radio frequency identification (RFID) technology to increase efficiency in the healthcare industry, Carr et al. (2014) used TAM as a basis of their framework and found a positive relationship between perceived of use and perceived usefulness of RFID technology. To test such relationships on IoT usage, the study proposes the following hypothesis:

H3. Perceived ease of use is a predictor of perceived usefulness

\section{Social Influence and Internet of Things (IoT) Usage}

The study conducted by Al-Momani et al. (2016) applied UTAUT's construct, i.e. social influence, which showed a positive effect on the behavioural intention to use IoT. As addressed by Lu et al. (2018), social influence is also one of the most important factors in IoT technology acceptance, especially in the early adoption stage. At this stage, most of the adopters lack the information about the new products and the individual represents his/her value and belief on the importance of others to believe that he/she should use the technology. According to Venkatesh et al. (2003), over time, the pressure to use the technology will be based on the experience of using the technology. In their study, it was suggested that the sensitivity to use the technology will be 
based on gender and age, as older workers are greater attention seekers.

Previous studies have also shown that social influence does not construct significantly on a voluntary basis, but it works differently when the use of technology is imposed. For this kind of situation, social influence directly affects the intention to use the technology and will fade over time. Likewise, for grassroots innovators, social influence operates on a voluntary basis by influencing the use of technology, which greatly depends on three mechanisms - compliance (comply with others' expectations and subject to punishment), internalisation, and identification (Nasir \& Subari, 2017). Therefore, the study acknowledges the following hypothesis: H4. Social influence is the predictor of Internet of Things (IoT) usage

\section{E. Technology Resistance and Internet of Things (IoT) Usage}

The extended Task-Technology Fit model (TTF), which comprises the combination of the existing TTF and Information System (IS) models with technology resistance as an additional variable, has been used to evaluate technology resistance and technology satisfaction on students' performance by several scholars (Mohd Daud \& Mohamed, 2009). The study's result showed no signs of technology resistance to the students' performance.

The same study on technology resistance and managerial performance was performed by (Mohd Daud et al., 2013). The result showed that there is no significant relation between technology resistance and managers' performance due to the fact that the mandated tasks will be done without hesitation.

In the case of grassroots innovators' sustainability, as they literally face hardship in their circle (Salleh et al., 2019), the reaction towards IoT usage is yet to be tested. The result of the reaction would be a different cause based on the circle they are in, such as personality, background, traits, attitudes, and experience (Tsai et al., 2019). Grassroots innovators normally use their tacit knowledge due to their limitations in resources. Most scholars believed that individuals are complacent to use the traditional method; therefore, in this study, technology resistance will affect the grassroots innovators' adoption to use the appropriate technology (Pattnaik \& Dhal, 2015). This is largely related to the informal setup and common knowledge practice (Cozzens \& Sutz,
2012). Considering the above, the study formulates the following hypothesis:

H5. Technology resistance is the predictor of Internet of Things (IoT) usage

\section{F. Relative Advantage and Internet of Things (IoT) Usage}

According to Rogers (1983), innovation is an idea, practice, or object that is perceived as new by an individual to adopt. It is the first move of an individual to acknowledge the innovation's existence with an option of accepting or rejecting, applying, and agreeing with the decision to use (Aizstrauta et al., 2015). There are five variables in the Diffusion of Innovation (DOI) theory by Rogers (1983). The measure to take effect is as follows:

Relative advantage refers to an innovation that is highly potential to be sustained, has a "wow" factor as compared to the previous innovations, reduced in cost, and high in quality. Similarly, grassroots innovators aim to produce affordable and quality products. For example, the facilitation provided by Malaysia Innovation Foundation or Yayasan Inovasi Malaysia (YIM) lifts the innovation sought by communities that are affordable and have a competitive price (YIM, 2017). Therefore, the hypothesis is formulated as follows:

H6. Relative advantage is the predictor of Internet of Things (IoT) usage

\section{G. Complexity and Internet of Things (IoT) Usage}

Complexity refers to users having difficulty understanding and using innovation. As individuals who come from rural areas, grassroots innovators have a complex socio-cultural system and their characters compromise the social, environmental, and economic contexts to be locally embedded in their innovative solutions, which requires high thinking order and skillset. In the study conducted by Poutanen and Soliman (2015), embracing complexity is among the vital lessons learnt for the system to evolve or coevolve to be able to meet the social, environmental, and economic needs at large. They further confirmed that the application of the complexity theory to innovation has yet to be tested. Therefore, the hypothesis below is created:

H7. Complexity is the predictor of Internet of Things (IoT) usage 


\section{H. Trialability and Internet of Things (IoT) Usage}

Trialability refers to the situation whereby users can have access to innovation on a trial basis at no cost. Grassroots innovators innovate organically from their surroundings of hardship and challenges. This phenomenon is known as "cradle to cradle", whereby their trial circle of products will never end, which is the opposite to the mainstream marketing strategy of "cradle to grave" product life cycle. As an example, trialability is used in accessing the functionality of new technologies as brought by the study on frugal smartphone diffusion in China and the US (Zhang, 2018). The current research is intended to test the following hypothesis:

H8. Trialability is the predictor to the Internet of Things (IoT) usage

\section{Observability and Internet of Things (IoT) Usage}

Observability refers to the ability of users to observe and comment on innovation. Communities act as the eyes and ears for their innovative local products. The tacit knowledge that inherited and garnered for generations is the best example. Grassroots innovators can make good judgments (Joshi et al., 2015). In the case of grassroots innovations, the innovations produced or used are based on daily chores to solve problems, using affordable materials and prudent decision making within their trust circle. Based on the evidence, this study proposes the following hypothesis:

H9. Observability is the predictor to the Internet of Things (IoT) usage

\section{J. Internet of Things (IoT) Usage and Grassroots Innovators' Sustainability}

IoT usage has been discussed widely in the research done by Pedrotti and Nistor (2016) for online learners, and AlMomani et al. (2016) for the adoption of IoT services. Furthermore, another study by Horn and Rennie (2018) entitled "Digital access, choice and agency in remote Sarawak", pointed out the opportunities and hurdles faced by users in rural Sarawak to access and use the Internet. The research suggested that the lack of accessibility to the Internet is a major drawback/determinant for them to use the Internet. From the study, improved accessibility to the Internet will result in more knowledge dissemination to the community, whereby the information on innovations under the government initiatives will become easily accessible. In addition to accessibility and knowledge dissemination, , IoT helps to build up skills and abilities. The above will be used as the dimensions to IoT usage.

To become sustainable, grassroots innovators need to realise the importance of IoT application in their life. Sustainability in this context is related to the innovations that they produce. According to Lai (2017), the development of a new theoretical research framework will be based on many factors that influence the context setting. In the case of grassroots innovators' sustainability, Sarkar and Pansera (2017) pointed out in their research "Sustainability-driven innovation at the bottom: Insights from grassroots ecopreneurs" that the sustainability-driven innovation dimension is focused on environmental integrity concerns. The cases analysed that grassroots innovators' sustainability is motivated by the problems that they are facing. The study concluded that grassroots innovations can be sustained with frugal innovation that will benefit the whole nation tremendously when successful.

As further emphasised by Dey et al. (2018) in their recent study on "Innovation, investment and enterprise: Climate resilient entrepreneurial pathways", it was described that the viability of innovation-based pathways for poverty alleviation rested on four assumptions as follows: a) a hub to gather innovations to reduce the related transaction costs; b) technology accessibility to the poor; c) realising the unmet needs; and d) using technologies as own choice and as a medium of communication sharing knowledge and practices to make innovation work and become sustainable. The study recommended that the total freedom for users to co-joint own an open source might help in promoting a better economy and offering sustainability to the grassroots innovators.

As this study touches on the innovation produced by the grassroots innovators and IoT is part of the most trendy and sought after technology nowadays, it is significant to predict the usage of IoT with grassroots innovators' sustainability. To test such a relation, the study puts forth the following hypothesis:

H1O. Internet of Things (IoT) Usage is a predictor of grassroots innovators' sustainability. 


\section{Research Framework Development}

IoT is believed to change the world via emerging innovative technologies (Nolin \& Olson, 2016) that contribute towards the economic growth and reduce the involvement of human intervention to enhance efficiency ( $\mathrm{Yu}$ et al., 2016). Nevertheless, IoT usually comes with risks that significantly influence customers' intention and behaviour (Gao \& Bai, 2014).

The conducted literature review pointed out several factors that influence IoT usage on grassroots innovators' sustainability in Malaysia. To develop the theoretical model of the influence of IoT usage, the study attempted to discover the term of IoT usage within TAM that explains the behaviour of the innovators in the context of their IoT usage. The study identified three prominent TAM models to be investigated with, namely Technology Acceptance Model (TAM) (Davis, 1989), Unified Theory of Acceptance and Use of Technology (UTAUT) (Venkatesh et al., 2003), and Diffusion of Innovation Theory (DOI) (Rogers, 2003), together with variables in the extended Task-Technology Fit (TTF) theory (Mohd Daud \& Mohamed, 2009). From the appended integrated theories combination, the study allowed to identify the significant variables input, whereby TAM addresses two output variables (perceived usefulness (PU) and perceived ease of use (PEOU)), UTAUT addresses four variables (performance expectancy, effort expectancy, social influence, and facilitating conditions), while DOI recognises five variables (relative advantages, complexity, trialability, observability, compatibility). The study was further concerned in the area related to the grassroots innovators' usage of IoT on other constructs and found that technology resistance (Mohd Daud \& Mohamed, 2016) as an extension of TTF is interesting enough to be tested in the aspect of IoT usage on grassroots innovators' sustainability.

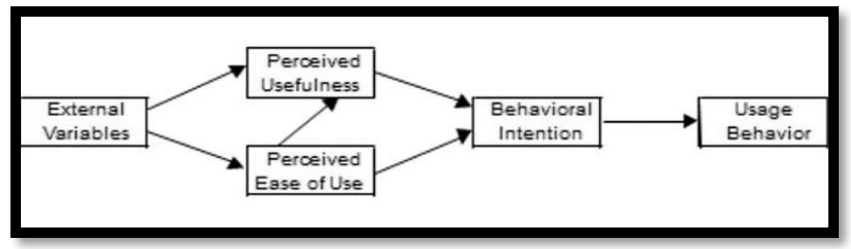

Figure 1. Technology Acceptance Model (Davis, 1989)

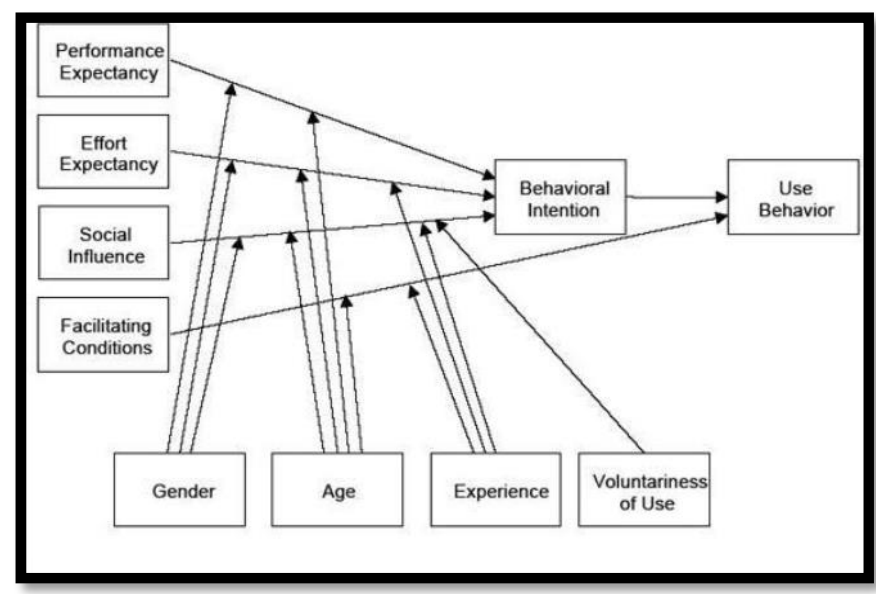

Figure 2. Unified Theory of Acceptance and Use of Technology (Venkatesh et al., 2003)

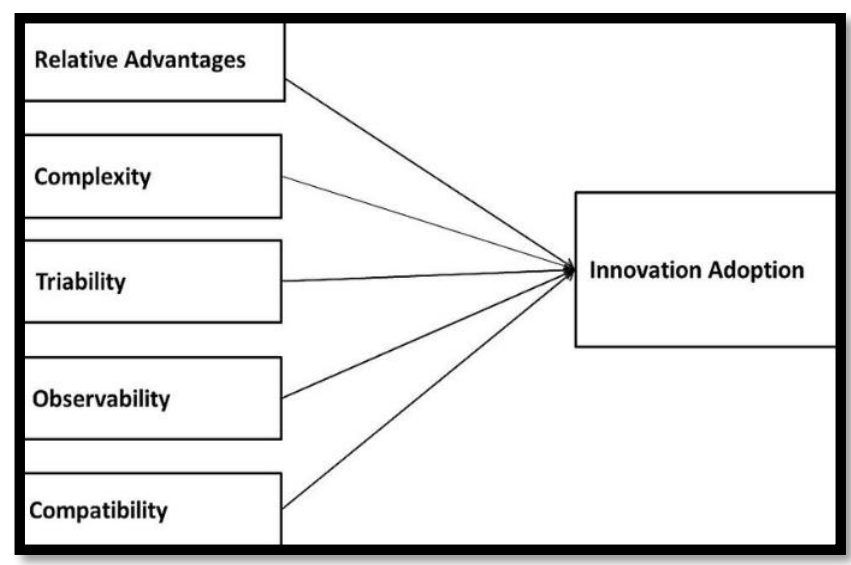

Figure 3. Diffusion Innovation Theory (Roger, 2003)

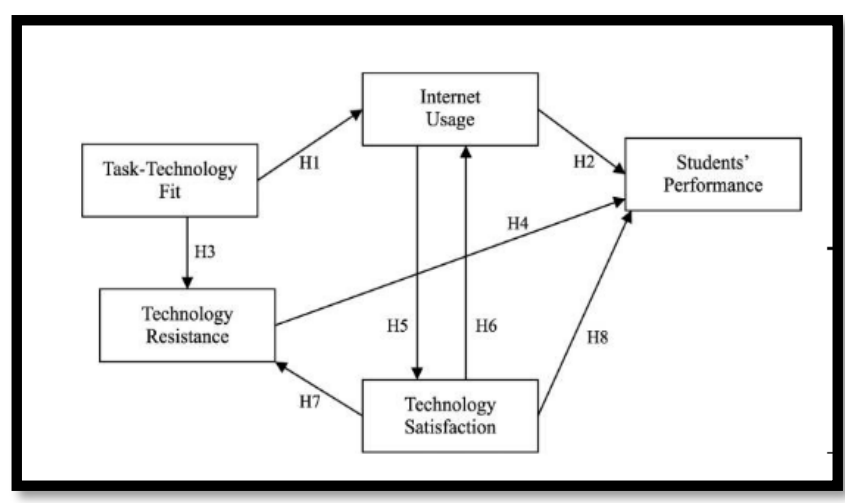

Figure 4. Extended Task-Technology Fit Model (Mohd Daud \& Mohamed, 2016)

Based on the above theories, the study was further extracted into the factors/determinants influencing grassroots innovators to use IoT. Perceived usefulness emphasised on knowledge enhancement, trust, and safety (Al-Momani et. al., 2016; Davis, 1989; Gao \& Bai, 2014). While the study found 
that perceived ease of use determinants are control, playfulness, emotion, and usability to enable innovators to use IoT applications (Venkatesh, 2004; Lu et. al., 2018; AlMomani et al., 2016).

Concurrently, the study discovered that not all variables from UTAUT were significant in the context of grassroots innovators' sustainability. There are weaknesses in UTAUT in terms of performance expectancy, effort expectancy, and facilitating conditions (Venkatesh, 2012; Owusu Kwateng et al., 2018). Grassroots innovators perform based on sustainability (Smith \& Seyfang, 2013) with no performance to be measured as their informal context setting, and this non-monetary element is precisely valued (Seyfang \& Smith, 2007).

Furthermore, in the case of grassroots innovators, they are prone to challenges with limitation in resources and their effort to sustain is purely based on any appropriate technology that appears to be useful (Pattnaik \& Dhal, 2015). Another study addressed that different beliefs reflect their condition at the grassroots level as compared to those with resourceful and formal context setting (Joshi et al., 2015). Therefore, only social influence is related to grassroots innovators' sustainability. Social influence is the extent to which individuals perceive that technology is vital to their circles (Venkatesh, 2012). Social influence refers to the degree to which an individual perceives the importance of others' belief that they should use a certain technology as it is one of the most crucial in IoT service and technology adaptation (Lu et. al., 2018; Gao \& Bai, 2014).

This variable takes the determinants of experience, gender, age, and voluntariness in line with the nature of grassroots innovators (Nasir \& Subari, 2017). Social influence is significant when the social network gives considerable attention to use the technology. For example, with the most recent phenomenon of social influence due to the COVID-19 pandemic in Malaysia, many initiatives have been done in an informal setting such Open Source COVID-19 Medical Supplies and 3D Printing Community, an open source public platform. The urge to help due to the hardship, challenges, and stewardship has attracted more than 52,000 members to join the effort and they become the most active and reliable backbones producing face shields, intubation boxes, and suits to the front liners in combating this pandemic.
Apart from that, social influence takes the highest credit when facilitating the transition process of adopting a new way of doing things in Korea's green growth initiative (Lee, Zusman, \& Lee, 2017). On the other hand, the extended TTF shows a positive relationship on Internet usage. Technology resistance is used to evaluate students' performance (Mohd Daud \& Mohamed, 2009).

In the case of this study, IoT usage is believed to be practised hand-in-hand seamlessly with sustainable innovation growth nationwide by 2020 (Bekhet \& Latif, 2018). IoT's huge potential is based on the National IoT Roadmap (MIMOS Berhad, 2016). Technology resistance with its determinants normally indicates a negative behaviour towards the usage of the technology. Ironically, the huge difference with other studies is that IoT usage is to be tested at the informal context setting.

Furthermore, this study realised that the explanation of further adoption process of technology usage and related diffusion of new technologies such as IoT are often based on the DOI theory established by Rogers (2003). DOI contributes towards the understanding by covering antecedents that have been neglected in TAM. DOI is interpreted when an individual perceives a new idea and the perceived newness, unlimited to the new knowledge of the subject matter, greatly depends on the user's reaction towards it. There are five variables to be considered in DOI, namely relative advantage, compatibility, complexity, trialability, and observability. As the nature of grassroots innovators is aiming to produce affordable and quality products, innovativeness is the key to their sustainability.

Grassroots innovators are good at applying traditional methods and indigenous knowledge, the innovation produced is capable to fulfil their unmet needs. Their trial circle of product is always "cradle to cradle" instead of "cradle to grave" in the mainstream business landscape. Their tacit knowledge that has been inherited for generations is proof that their innovations are always an added value from time to time and their communities are their real eyes and ears for observation purposes. Therefore, relative advantage, complexity, trialability and observability are significant in each of the above factors/determinants, the study further investigates further the dimensions/criteria/measurable extent related to the factor/determinants that would 
influence the usage of IoT, which represents the external and internal forces.

The relationship between independent variables and their dimensions with dependent variables and their dimensions is further mediated by IoT usage to investigate the effect of the relationship. IoT usage shows a significant impact in translating business innovations into economic development (Yu et al., 2016). Areas of improvement include IoT ventures, network integration between players, reduction for company transaction costs, and reduced human intervention (Grau, 2013). Consequently, this gives impact to four levels of IoT services (Lu et al., 2018), namely infrastructural, organisational level, and individual levels, as well as allinclusive levels consisting of transportation, medical and healthcare, and education.

The importance of IoT has been shown in many areas and levels as part of knowledge capability. IoT also represents the extent to acquire and disseminate knowledge, which may lead to novel interpretation and recombination of market knowledge and offerings, including product and process innovations (Chowdhury \& Raut, 2018). Therefore, the purpose of mediation analysis is to examine the strength of the influence of IoT usage (mediator) to compare with the direct influence of the independent variables towards dependent variables (grassroots innovators' sustainability).

The dimensions of IoT usage as the mediating variables (accessibility, knowledge dissemination) are further investigated to observe the influence of contributing factors towards grassroots innovators' sustainability. The grassroots innovators' sustainability relates to the innovations that they produce using IoT applications. The development of the research framework will be based on many factors of sustainability (Sarkar \& Pansera, 2017; Lai, 2017).

The cases further analysed that grassroots innovators' sustainability is motivated by the problems that they are facing. In realisation to solve the problems, the need for a common platform using technologies and sharing knowledge to match the unmet needs to signify the sustainability is vital (Dey et al., 2018). Therefore, grassroots innovators' sustainability determinants are environmental integrity, common hub, technology accessibility, realisation of unmet needs, and knowledge sharing. The integrated and merging of theories are extracted from those output variables relevant to the grassroots innovators being recognised to develop a new framework.

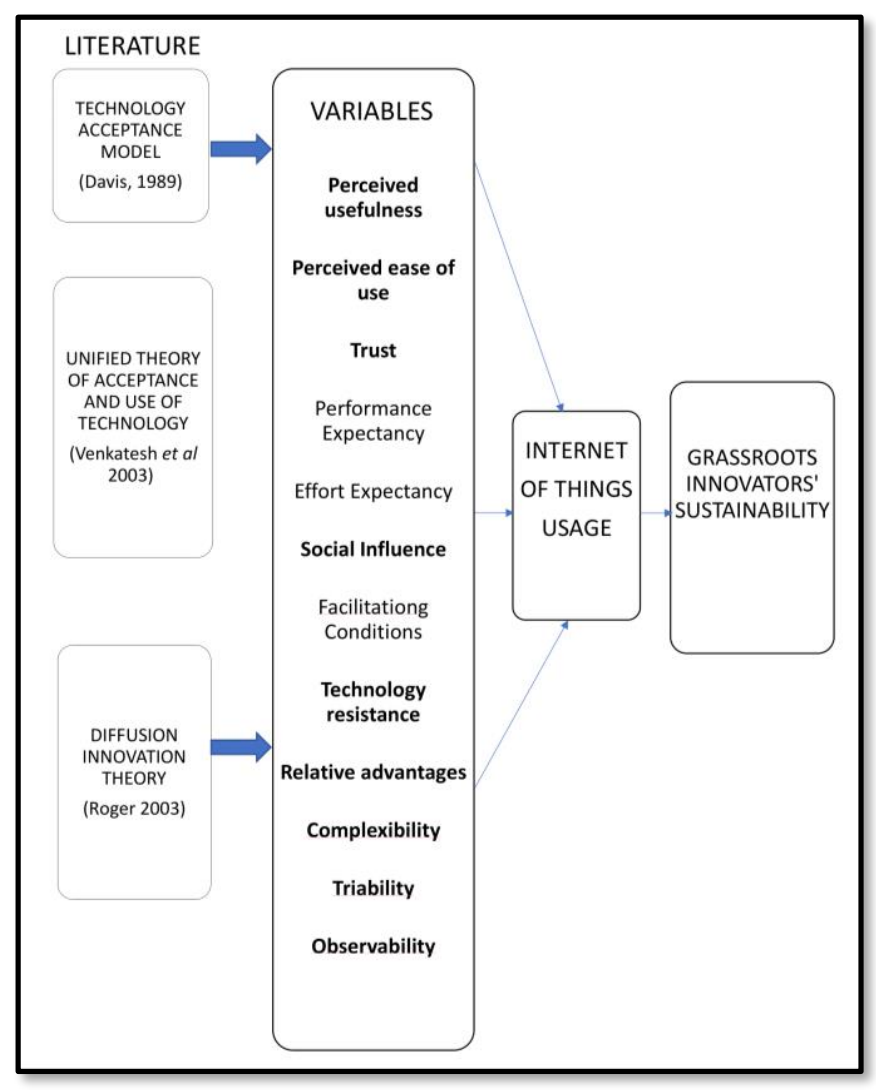

Figure 5. Basic framework

\section{Theoretical Framework}

Key concepts and relevant theories tested by previous scholars would be the pillar and sources of the study. This combination of theories will become the basis of the belief that explains how certain problems existing in the grassroots innovators' sustainability are related to each other. Based on the importance of IoT usage on grassroots innovators' sustainability, it is vital to associate these theories and explanations are made possible by the integration of variables to obtain an optimum result and better insight to unearth the solutions. 


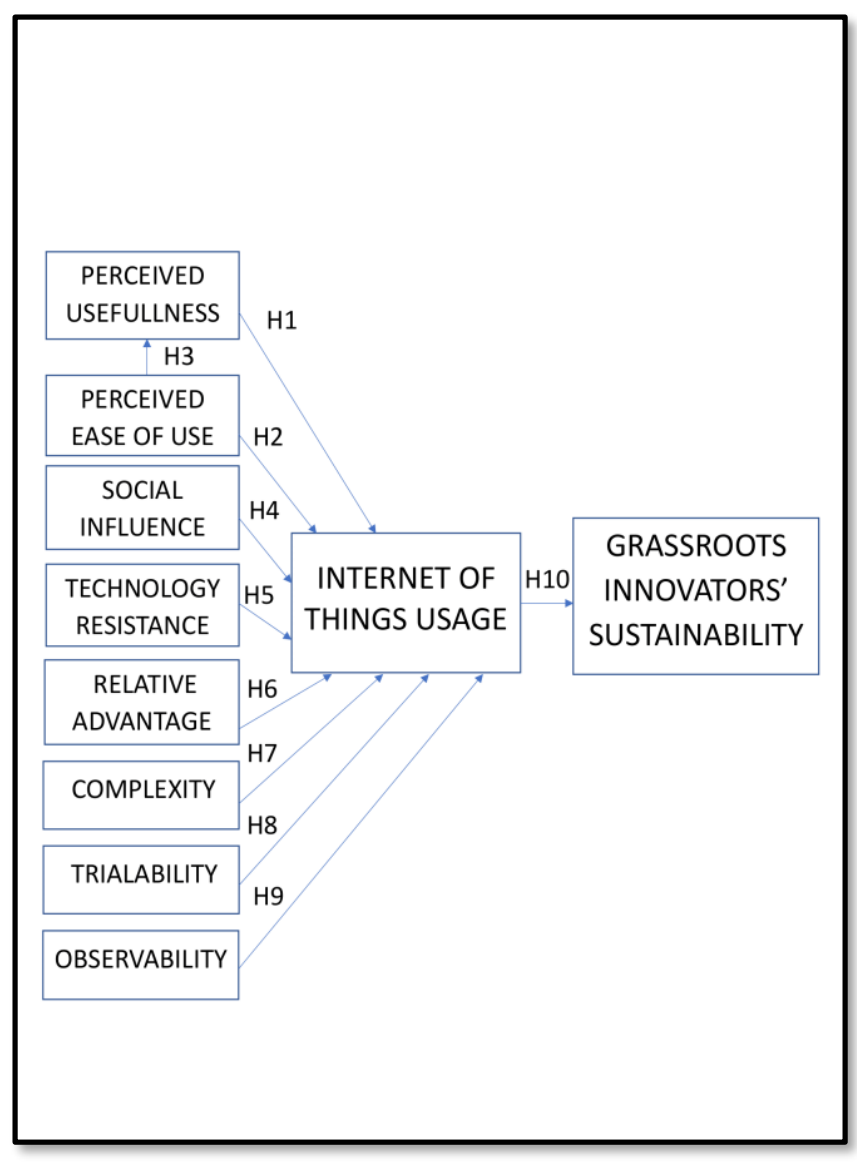

Figure 6. Theoretical framework

\section{Conceptual Framework}

Based on the previous scholars: Davis (1989) for TAM, Venkatesh et al. (2003) for UTAUT, Rogers (2003) for DOI and (Mohd Daud \& Mohamed, 2009) for extended TTF, this study considered the similarities between the determinants found. Based on the understanding of the similarities, understanding of the words, functions, and definitions, the conceptual framework of this study is constructed as below. The conceptual framework will be tested accordingly on the influence of IoT on grassroots innovators' sustainability in Malaysia.

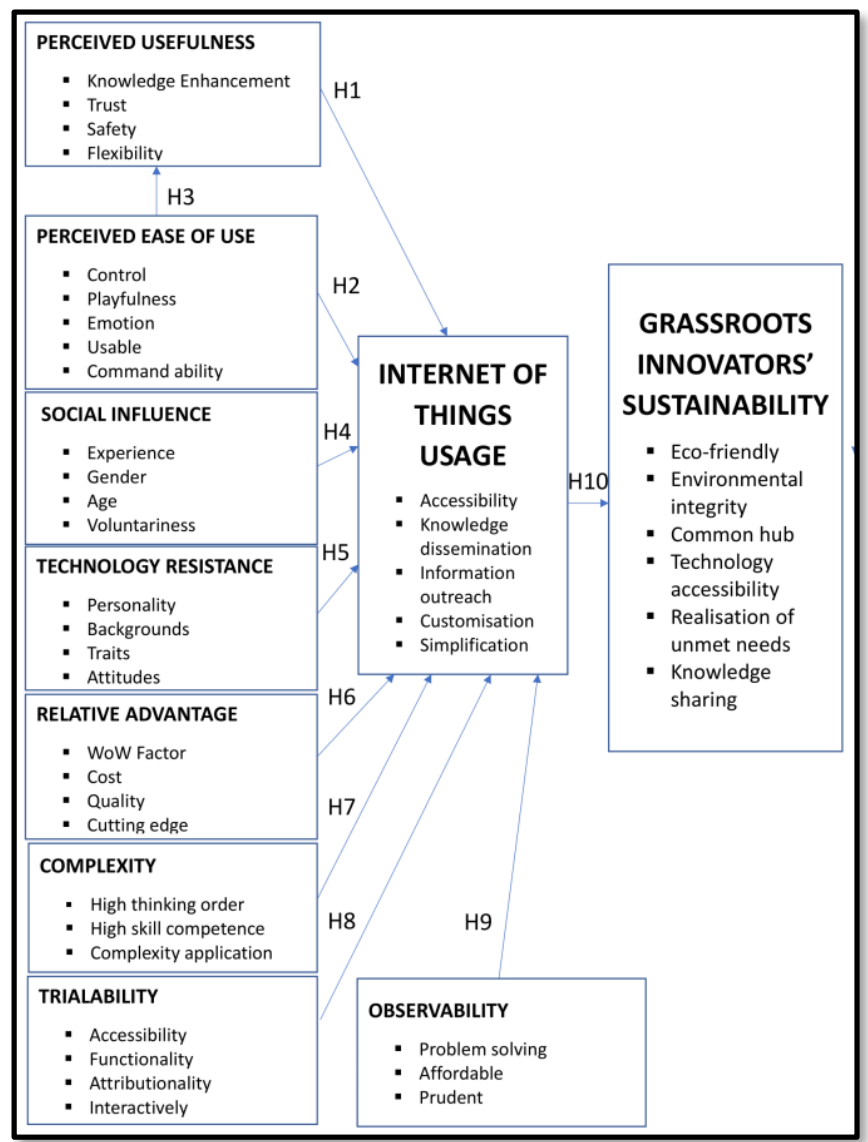

Figure 7. Conceptual framework

\section{Hypothesis Study}

H1: Perceived usefulness is a predictor of internet of things (IoT) usage

H2: Perceived ease of use is a predictor of internet of things (IoT) usage

H3: Perceived ease of use is a predictor of perceived usefulness

H4: Social influence is a predictor of internet of things (IoT) usage

$\mathrm{H}_{5}$ : Technology resistance is a predictor of internet of things (IoT) usage

H6: Relative Advantage is a predictor of internet of things (IoT) usage

H7: Complexity is the predictor of internet of things (IoT) usage

H8: Trialability is the predictor of internet of things (IoT) usage.

H9: Observability is the predictor of internet of things (IoT) usage

H10: Internet of things (IoT) usage is a predictor of Grassroots Innovators' sustainability 
There are several factors that influence IoT usage on grassroots innovators' sustainability in Malaysia. For instance, Technology Acceptance Model (Gao \& Bai, 2014; Rahayu \& Day, 2017; Hubert et. al., 2018; Smith \& Seyfang, 2013; Venkatesh, 2012; Seyfang, 2007), Unified Theory of Acceptance and Use of Technology (Venkatesh et al., 2003), innovation adoption (Rogers, 2002; Aizstrauta et al., 2015), and technology resistance (Mohd Daud \& Mohamed, 2009).

Therefore, to validate and investigate such integrated relations, this study will test each factor, namely perceived usefulness, perceived ease of use, social influence, technology resistance, relative advantage, complexity, trialability, and observability as a predictor of IoT usage. IoT usage is treated as a predictor of grassroots innovators' sustainability. Although the study might not exhaustively cover the effect of IoT usage on grassroots innovators' sustainability, it will give adequate insight and important determinants in assessing the conceptual framework of the focus area in Malaysia.

The conceptual framework is useful to underlie the constructed concepts that are zooming into the niche area, which is also a distinction from the related theories previously found. The study will take forth grassroots innovators from the current population of 4,000 innovators (YIM, 2017). 335 respondents from six zones, i.e. East Coast, Southern, Northern, Central, Sabah and Sarawak who have accessibility to the Internet, are smartphone owners, and familiar with IoT function and applications will be selected. Federal Territory is not included as the location is in urban areas. Stratified random sampling is used when assessing different information needed in each layer of the population that is not in the same area (Sekaran \& Bougie, 2016).

\section{RESULT AND DISCUSSION}

As this study concurs on rural innovators, it mainly focuses on the influence of the Internet of things usage on grassroots innovators to be sustained. The study expected outcome are: i) By using IoT applications, the grassroots innovators will improve their innovation from functionality to pre commercialisation means and gain beyond non-profit reason.

ii) By using IoT applications will help the grassroots innovators to embrace technology embedded in their tacit knowledge and fine-tune with the scientific findings. Thus, integration of tacit knowledge and sciences would be accepted in the mainstream economy.

iii) Grassroots innovators readiness to use IoT in the development of their innovations give a wide window of opportunity to replicate, re-engineer and readapt elsewhere.

\section{CONCLUSION}

Given the practicality, the study provides understanding on the important insights to the relevant authorities and stakeholders in terms of identifying strategies to enhance the usage of internet of things on grassroots innovators to ensure their sustainability in the area of environmental issues, societal structures and economic importance. For example, some corrective measures actions are deemed essential to ensure the people at rural and $\mathrm{B} 40$ are not left behind in term of accessibility and affordability of the internet of things applications. The realisation to unearth the importance of the grassroots innovators as they might be poor but not necessarily poor in knowledge. The corrective measures help the government to continue to build a knowledge-based economy nation. Future planning in the next Malaysia plans to include more B40 participation in science, technology and innovation. A full force programs' implementation for grassroots innovators should be encouraged to prosper sustainability in a systematic platform, specifically using internet of things as part of the science, technology and innovation's pulse.

\section{ACKNOWLEDGEMENT}

I sincerely thank Yayasan Inovasi Malaysia for providing me first hand information. My special gratitude to my supervisor, Professor Dr Norzaidi Mohd Daud for his continuous support and encouragement. 


\section{REFERENCES}

Aizstrauta, D, Ginters, E, \& Eroles, MAP 2015, 'Applying theory of diffusion of innovations to evaluate technology acceptance and sustainability', Procedia Computer Science, vol. 43(C), pp. 69-77. doi: 10.1016/j.procs.2014.12.010.

Al-Momani, AM, Mahmoud, MA \& Ahmad, MS 2016, 'Modeling the adoption of internet of things services: a conceptual framework', International Journal of Applied Research, vol. 2, no. 5, pp. 361-367.

Bekhet, HA \& Latif, NWA 2018, 'The impact of technological innovation and governance institution quality on Malaysia's sustainable growth: evidence from a dynamic relationship', Technology in Society, vol. 54, pp. 27-40. doi: 10.1016/j.techsoc.2018.01.014.

Carr, AS, Zhang, M, Klopping, I, Min, H, Carr, AS \& Green, B 2014, 'RFID technology: implications for healthcare organizations', American Journal of Business, vol. 25, no. 2, pp. 25-40. doi: 10.1016/j.ijpe.2014.09.034.

Siwar, C, Ahmed, F, Bashawir, A \& Mia, MS 2016, 'Urbanization and urban poverty in Malaysia: consequences and vulnerability', Journal of Applied Sciences, vol. 16, no. 4, pp.154-160.

Chatterjee, S \& Kar, AK 2018, 'Effects of successful adoption of information technology enabled services in proposed smart cities of India: from user experience perspective', Journal of Science and Technology Policy Management, vol. 9, no. 2, pp. 189-209. doi: 10.1108/JSTPM-03-2017-0008.

Chowdhury, A \& Raut, SA 2018, 'A survey study on internet of things resource management', Journal of Network and Computer Applications, vol. 120, pp. 42-60. doi: 10.1016/j.jnca.2018.07.007

Cozzens, SE \& Sutz, J 2012, 'Innovation in informal settings: a research agenda executive summary innovation in informal settings', A Research Agenda, pp. 1-53.

Davies, A 2012, Enterprising communities: grassroots sustainability innovations, Emerald Group Publishing Limited, UK.

Davis, FD 1989, 'Perceived usefulness, perceived ease of use, and user acceptance of information technology', MIS Quarterly, vol. 13, no. 3, pp. 319-340, $<$ https://www.jstor.org/stable/2490o8?seq=1\#page_scan _tab_contents $>$.

Decker, R \& Stummer, C 2017, 'Marketing management for consumer products in the era of the internet of things',
Advances in Internet of Things, vol. 7, no. 3, pp. 47-70. doi: 10.4236/ait.2017.73004.

Dey, A, Gupta, AK \& Singh, G 2018, Agricultural_Systems.pdf, Agricultural Systems.

Ejdys, J 2018, 'Building technology trust in ICT application at a University', International Journal of Emerging Markets. doi: 10.1108/IJoEM-07-2017-0234.

Gao, L \& Bai, X 2014, 'A unified perspective on the factors influencing consumer acceptance of internet of things technology', Asia Pacific Journal of Marketing and Logistics, vol. 26, no. 2, pp. 211-231. doi: 10.1108/APJML06-2013-0061.

Ghazali, EM, Mutum, DS, Chong, JH \& Nguyen, B 2018, 'Do consumers want mobile commerce? A closer look at mshopping and technology adoption in Malaysia', Asia Pacific Journal of Marketing and Logistics. doi: 10.1108/APJML05-2017-0093.

Grau, A 2013, The Internet of Things. Communications \& Strategies. doi: 10.5480/1536-5026-34.1.63.

Horn, C \& Rennie, E 2018, 'Digital access, choice and agency in remote Sarawak', Telematics and Informatics, vol. 35, no. 7, pp. 1935-1948. doi: 10.1016/j.tele.2018.06.006.

Hubert, M, Blut, M, Brock, C, Zhang, RW, Koch, V \& Riedl, R 2018, 'The influence of acceptance and adoption drivers on smart home usage', European Journal of Marketing. doi: 10.1108/EJM-12-2016-0794.

Jayashankar, P, Nilakanta, S, Johnston, WJ, Gill, P \& Burres, $\mathrm{R}$ 2018, 'IoT adoption in agriculture: the role of trust, perceived value and risk', Journal of Business and Industrial Marketing. doi: 10.1108/JBIM-01-2018-0023.

Joshi, RG, Chelliah, J \& Ramanathan, V 2015, 'Exploring grassroots innovation phenomenon through the lived experience of an Indian grassroots innovator', South Asian Journal of Global Business Research, vol. 4, no. 1, pp. 2744. doi: 10.1108/SAJGBR-01-2014-0003.

Kassim, ES, Jailani, SFAK, Hairuddin, H \& Zamzuri, NH 2012, 'Information system acceptance and user satisfaction: the mediating role of trust', Procedia-Social and Behavioral Sciences, vol. 57, pp. 412-418. doi: 10.1016/j.sbspro.2012.09.1205.

Lai, PC 2017, 'The literature review of technology adoption models and theories for the novelty technology', JISTEMJournal of Information Systems and Technology 
Management, vol. 14, no. 1, pp. 21-38. doi: 10.4301/S180717752017000100002.

Lee, SY, Zusman, E \& Lee, S 2017, 'Tracing sustainability transitions in Seoul governance: enabling and scaling grassroots innovations', Procedia Engineering, vol. 198, pp. 293-304. doi: 10.1016/j.proeng.2017.07.162.

Leminen, S, Rajahonka, M, Westerlund, M \& Wendelin, R 2018, 'The future of the internet of things: toward heterarchical ecosystems and service business models', Journal of Business \& Industrial Marketing, vol. 33, no. 6, pp. 749-767. doi: 10.1108/JBIM-10-2015-0206.

Lu, Y, Papagiannidis, S \& Alamanos, E 2018, 'Internet of things: a systematic review of the business literature from the user and organisational perspectives', Technological Forecasting and Social Change, (July 2016), 0-1. doi: 10.1016/j.techfore.2018.01.022.

Martin, CJ \& Upham, P 2016, 'Grassroots social innovation and the mobilisation of values in collaborative consumption: a conceptual model', Journal of Cleaner Production, vol. 134, pp. 204-213. doi: 10.1016/j.jclepro.2015.04.062.

Martiskainen, M 2017, 'The role of community leadership in the development of grassroots innovations', Environmental Innovation and Societal Transitions, vol. 22, pp. 78-89.

MIMOS Berhad 2016, National Internet of Things (IoT) strategic roadmap: a summary, <http://www.mimos.my/iot/National_IoT_Strategic_Roa dmap_Summary.pdf $>$.

Mohamed, H, Judi, HM, Nor, SFM \& Yusof, ZM 2012, 'Bridging digital divide: a study on ICT literacy among students in Malaysian rural areas', Australian Journal of Basic and Applied Sciences, vol. 6, no. 7, pp. 39-45.

Mohamed Salleh, S \& Mohd Daud, N 2019, 'Probing the influence of Internet of Things (IoT) usage on the grassroots innovators' sustainability: a Malaysian perspective', vol. 7 , no. 4, pp. 181-195.

Mohamed Salleh, S \& Othman, O 2016, Young Innovator Program (01), Kuala Lumpur, < https://www.igem.my/data/editor/download/SHOW >.

Mohd Daud, N \& Mohamed, IS 2009, 'Evaluating technology resistance and technology satisfaction on students' performance', Campus-Wide Information Systems, vol. 26, no. 4, pp. 298-312. doi: 10.1108/10650740910984637.

Mohd Daud, N \& Mohamed, IS 2016, 'Evaluating technology resistance and technology satisfaction on students' performance', Campus-Wide Information Systems
Emerald Article, Mohd Daud Norzaidi, Mohamed Intan Salwani, (March).

Mohd Daud, N, Mohamed, IS, Alghanim, S \& Alhamali, R 2013, 'Investigating the impact of intranet resistance and intranet withdrawal in Malaysian maritime industry', Polish Maritime Research, vol. 21, no. 1, pp. 89-95. doi: 10.2478/pomr-2014-0012.

Mujahid, YH 2001, 'Digital opportunity initiative for Pakistan', Pakistan Development Review, vol. 40, pp. 911928. doi: 10.1002/j.1681-4835.2002.tbooo50.x.

Nasir, NR \& Subari, MD 2017, 'A review of social innovation initiatives in Malaysia', Journal of Science, Technology and Innovation Policy', vol. 3, no. 1, pp. 10-17.

Nicolosi, E, Medina, R \& Feola, G 2018, 'Grassroots innovations for sustainability in the United States: a spatial analysis', Applied Geography, vol. 91, pp. 55-69. doi: 10.1016/j.apgeog.2017.12.024.

Nolin, J \& Olson, $N$ 2016, 'The Internet of Things and convenience', Internet Research, vol. 26, no. 2, pp. 360376. doi: 10.1108/IntR-03-2014-0082.

NST 2018, Mobile Cellular Penetration Reaches 131.8\%, $<$ https://www.thestar.com.my/business/businessnews/2018/02/14/mobile-cellular-penetration-reaches$1318 />$.

Osman, MA, Talib, AZ \& Sanusi, ZA 2012, 'A study of the trend of smartphone and its usage behavior in Malaysia', vol. 2, no. 1, pp. 275-286.

Owusu Kwateng, K, Osei Atiemo, KA \& Appiah, C 2018, 'Acceptance and use of mobile banking: an application of UTAUT2', Journal of Enterprise Information Management. doi: 10.1108/JEIM-03-2018-0055.

Pattnaik, BK \& Dhal, D 2015, 'Mobilizing from appropriate technologies to sustainable technologies based on grassroots innovations', Technology in Society, vol. 40, pp. 93-110. doi: 10.1016/j.techsoc.2014.09.002.

Pedrotti, M \& Nistor, $\mathrm{N}$ 2016, 'User motivation and technology acceptance in online learning environments, vol. 2, pp. 472-477. doi: 10.1007/978-3-319-45153-4.

Poutanen, P \& Soliman, W 2015, Complexity and organizational communication: a quest for common ground. doi: 10.1177/1534484316639713.

Rahayu, R \& Day, J 2017, 'E-commerce adoption by SMEs in developing countries: evidence from Indonesia', Eurasian Business Review, vol. 7, no. 1, pp. 25-41. doi: 10.1007/s40821-016-0044-6.

Rogers, EM 1983, Diffusion of innovations, (T. F. Press, I. A Division of Macmillan Publishing Co., \& N. Y. 10022866 
Third Avenue, New York, Eds.), 3rd edn, The Free Press A Division of Macmillan Publishing Co., Inc. 866 Third Avenue, New York, N.Y. 10022, $<$ https://teddykw2.files.wordpress.com/2012/o7/everettm-rogers-diffusion-of-innovations.pdf $>$.

Rogers, EM 2002, Diffusion of preventive innovations, vol. 27, pp. 989-993, $<$ http://search.proquest.com/docview/72159136?pqorigsite $=$ summon $>$.

Rogers, EM 2003, Diffusion of innovations, (EM Rogers, Ed) 3rd edn, FreePress, New York. doi: 10.1007/s10661-0143885-4.

Rouse, M 2005, ICT (Information and Communications Technology or Technologies, <https://searchcio.techtarget.com/definition/ICTinformation-and-communications-technology-ortechnologies $>$.

Sarkar, S \& Pansera, M 2017, 'Sustainability-driven innovation at the bottom: insights from grassroots ecopreneurs', Technological Forecasting and Social Change, vol. 114, pp. 327-338. doi 10.1016/j.techfore.2016.08.029.

Sekaran, U \& Bougie, R 2016, Research methods for business: a skill building approach, 7 th edn, John Wiley \& Sons, UK.

Seyfang, G \& Smith, A 2007, 'Grassroots innovations for sustainable development: towards a new research and policy agenda', vol. 16, no. 4, pp. 584-603. doi: 10.1080/09644010701419121.

Siwar, C, Ahmed, F, Bashawir, A \& Mia, MS 2016, 'Urbanization and urban poverty in Malaysia: Consequences and vulnerability', Journal of Applied Sciences, vol. 16, no. 4, pp. 154-16o. doi: 10.3923/jas.2016.154.160.

Smith, A, Fressoli, M \& Thomas, H 2014, 'Grassroots innovation movements: challenges and contributions', Journal of Cleaner Production, vol. 63, pp. 114-124. doi: 10.1016/j.jclepro.2012.12.025.

Smith, A \& Seyfang, G 2013, 'Constructing grassroots innovations for sustainability', Global Environmental Change, vol. 23, no. 5, pp. 827-829. doi: 10.1016/j.gloenvcha.2013.07.003.

Tahir, Zurinah, Jalaludin, Abdul Malik, Ibrahim, MA 2016, 'Developing smart ICT in rural communities in Malaysia through the establishment of Telecenters', E-Bangi, vol. 11, no. 1, pp. 227-242.

Tsai, J, Cheng, M, Tsai, H, Hung, S \& Chen, Y 2019, 'The perspective of dual-factor concepts in technology adoption',
International Journal of Information Management Acceptance and Resistance of Telehealth, vol. 49, pp. 3444.

Venkatesh, Viswanath 2004, Determinants of perceived ease of use: integrating control, intrinsic motivation, and emotion into the technology acceptance model, Cognitiva, vol. 16, no. $1, \quad$ pp. 3-11, <jmtoro@psi.ub.es\%5Cn10.1174/o21435504322839135\%5 Cnhttp://search.ebscohost.com/login.aspx?direct=true\&d $\mathrm{b}=$ psyh\&AN=2004-12320-001\&lang=es\&site=ehost-live $>$. Venkatesh, Viswanath 2012, 'Consumer acceptance and use of information technology: extending the unified theory of acceptance and use of technology', MIS Quarterly, vol. 36, no. 1 , pp. 157-178.

Venkatesh, Viswaneth \& Michael G, Morris, Gordon BDavis, FDD 2003, 'User acceptance of information technology: toward a unified view', MIS Quarterly, vol. 27, no. 3, pp. 425-478. doi:10.1006/mvre.1994.1019.

YIM 2017, Mainstreaming grassroots innovations, $<$ yim.my $>$.

$\mathrm{Yu}, \mathrm{X}$, Nguyen, B \& Chen, Y 2016, 'Internet of things capability and alliance: entrepreneurial orientation, market orientation and product and process innovation', Internet Research, vol. 26, no. 2, pp. 402-434. doi: 10.1108/IntR10-2014-0265.

Zhang, L \& Mahadevia, D 2014, 'Translating science and technology policies and programs into grassroots innovations in China', Journal of Science and Technology Policy Management, vol. 5, no. 1, pp. 4-23. doi: 10.1108/JSTPM-03-2014-0007.

Zhang, X 2018, 'Frugal innovation and the digital divide: developing an extended model of the diffusion of innovations', International Journal of Innovation Studies, vol. 2, no. 2, pp. 53-64. doi: 10.1016/j.ijis.2018.06.001. 